\title{
新的可变形 $\mathrm{Fe}-\mathrm{C}_{\mathrm{r}}-\mathrm{Co}_{0}$ 系永磁合金
}

\section{齐 凤 春 \\ 一、引 忘}

在永磁材料中,目前产量最大和应用最广的铸造铝镍钴合金和铁氧体永磁体,以及新出现 的稀土钴永磁合金, 其共同的缺点, 是机械性能不好, 很脆, 或者既脆且硬, 只能研磨, 不能进行 其它方面的机械加工. 因此, 它们在应用上就受到一定的限制. 虽然已经有一些可变形永磁 合金,但其性能都不高 (参看表 1).

表 1 传统的可变形永磁合金

\begin{tabular}{|c|c|c|c|c|c|c|c|c|c|}
\hline 合 & & 金 & 成 分 & （重量\%） & $\mathrm{Br}$ & （高斯） & $\mathrm{Hc}$ & （奥斯特） & $(\mathrm{BH})_{m}$ (北高 - 奥) \\
\hline 铜 & 镍 & 铁 I & $60 \mathrm{Cu}, 20 \mathrm{Ni}$ & $2.5 \mathrm{Co}$, 余 $\mathrm{Fe}$ & & 5800 & & 590 & 1.9 \\
\hline 铜 & 镍 & 铁 II & $50 \mathrm{Cu}, 20 \mathrm{Ni}$ & 余 $\mathrm{Fe}$ & & 7300 & & 260 & $0.7 \sim 0.8$ \\
\hline 铜 & 镍 & 钴 I & $50 \mathrm{Cu}, 21 \mathrm{Ni}$ & $29 \mathrm{Co}$ & & 3400 & & $60 \sim 710$ & $0.8 \sim 1.0$ \\
\hline 铜 & 镍 & 钴 II & $35 \mathrm{Cu}, 24 \mathrm{Ni}$ & $41 \mathrm{Co}$ & & 5300 & & 450 & 1.0 \\
\hline 铁 钴 & 钒 I & (线材) & $52 \mathrm{Co}, 14 \mathrm{~V}$ & 余 $\mathrm{Fe}$ & & 10000 & & 520 & 3.5 \\
\hline 铁 钴 & 钒 II & (板材) & 同 & 上 & & 10000 & & 300 & 1.8 \\
\hline
\end{tabular}

可变形铂钴合金的矫顾力和磁能积较高，最近它的磁性能又有突破(矫顾力: 由 4300 提 到 4900 奥斯特; 磁能积: 由 9.5 提高到 15.0 兆高 - 奥; 剩磁: 由 6450 提到 8300 高斯). 但 是,最大的问题,是这种合金十分昂贵,所以它的应用便受到很大限制.

近年来, 新出现的可变形 $\mathrm{Fe}-\mathrm{Cr}-\mathrm{Co}$ 系合金,其磁性能竟达到铝镍钴 5 合金的水平,价格 也不昂贵. 现把该系合金的最近水平示于表 2 .

表 2 新的可变形 $\mathrm{Fe}-\mathrm{Cr}-\mathrm{Co}$ 系永磁合金

\begin{tabular}{|c|c|c|c|c|c|c|}
\hline 金 & （重量\%） & （高斯） & $\mathrm{Hc}$ & （奥斯特） & $(\mathrm{BH})_{m}$ (兆高 - 奥) & 资 料 \\
\hline 铁 铬 钴 & $31 \mathrm{Cr}, 23 \mathrm{Co}$, 余 $\mathrm{Fe}$ & 11500 & & 660 & 4.1 & [1] \\
\hline 铁铬钴钼 & $30 \mathrm{Cr}, 25 \mathrm{Co}, 3 \mathrm{Mo}$, 余 $\mathrm{Fe}$ & 11500 & & 780 & 5.0 & {$[1]$} \\
\hline 铁铬钴砫 I & $28 \mathrm{Cr}, 23 \mathrm{Co}, 1 \mathrm{Si}$, 余 $\mathrm{Fe}$ & 13000 & & 580 & $5.3^{*}$ & {$\left[\begin{array}{l}2 \\
3\end{array}\right]$} \\
\hline 铁铬钴硅 II & $27.7 \mathrm{Cr}, 23 \mathrm{Co}, 0.8 \mathrm{Si}$, 余 $\mathrm{Fe}$ & 11900 & & 725 . & 5.0 & [ 4 ] \\
\hline
\end{tabular}

* 热磁处理后,再沿磁场方向加工, 则 $(\mathrm{BH})_{m}$ 可近似达到 7 兆高 - 奧 ${ }^{[5]}$.

在磁性热处理前, $\mathrm{Fe}-\mathrm{Cr}-\mathrm{Co}$ 系永磁合金可以进行切削和塑性加工,因此,它可以做成任 意形状和尺寸的永磁体. 在锻造、轧制和拉丝等加工时，不必考虑加工方向，因为磁各向异性 是加工后经过热处理给出的. 图 1 给出了该种合金的退磁曲线.

最近, 日本以 “CKS-1”牌号生产的 $\mathrm{Fe}-\mathrm{Cr}$ - $\mathrm{Co}$ 系永磁合金, 其工业生产水平: 矫㖇力为 $600 \sim 730$ 奥斯特, 剩磁为 10500 11500 高斯, 磁能积为 $3.5 \sim 4.5$ 兆高 - 奥. 该种合金, 可以做 
成板材和条材 (从 7 0.1 毫米)的异形永磁体. 可用于速度计、定时马达等方面. 也可做成线 材和棒材 (从 $\phi 15 \sim \phi 0.5$ 毫米) 的圆柱形和角柱形的永磁体. 可用于钟表、笛簧接点、指针测 微器等方面.

$\mathrm{Fe}-\mathrm{Cr}-\mathrm{Co}$ 系永磁合金的机械性能和物理性能示于表 3 和表 4.

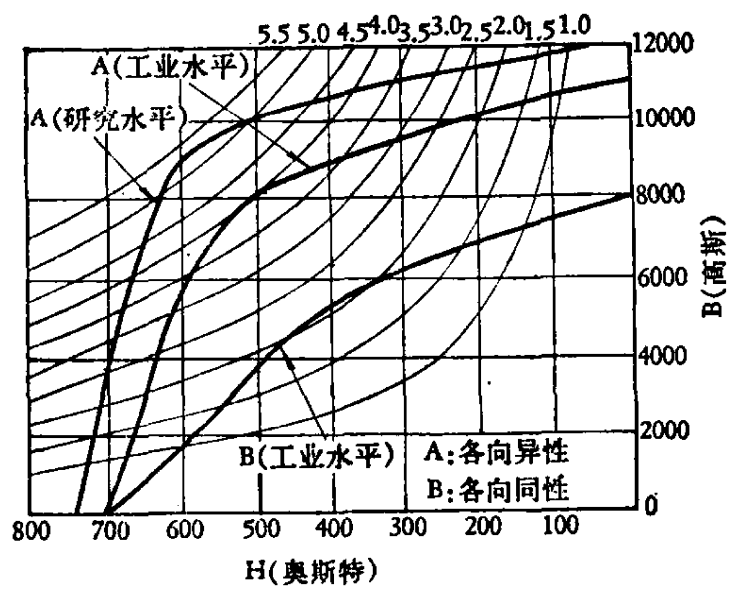

图 $1 \mathrm{Fe}-\mathrm{Cr}-\mathrm{Co}$ 系永磁合金的退磁曲线
表 $3 \mathrm{Fe}-\mathrm{Cr}-\mathrm{Co}$ 系永磁合金的机械性能

\begin{tabular}{|c|c|c|c|}
\hline 性 & 轧制后 & $\begin{array}{c}\text { 中间热处 } \\
\text { 理后 }\end{array}$ & $\begin{array}{c}\text { 磁性热处 } \\
\text { 理后 }\end{array}$ \\
\hline HRc & $25 \sim 30$ & $20 \sim 25$ & $50 \sim 55$ \\
\hline 拉伸强度（公厅/ 毫米 ${ }^{2}$ ) & $110 \sim 120$ & $60 \sim 75$ & $20 \sim 30$ \\
\hline 延 伸 率 (\%) & $4 \sim 10$ & $20 \sim 25$ & 1 \\
\hline
\end{tabular}

表 $4 \mathrm{Fe}-\mathrm{Cr}$ - $\mathrm{Co}$ 系永磁合金的物理性能

\begin{tabular}{c|c|c}
\hline 比 重 & 电阻率(微欧-厘米) & 热膨 胀 系 数 \\
\hline 7.7 & 75 & $10.0 \times 10^{-6}$ \\
\hline
\end{tabular}

这种新的斯皮诺答尔 (Spinodal) 型可变形 $\mathrm{Fe}-\mathrm{Cr}-\mathrm{Co}$ 系永磁合金, 是很有发展前途的, 目 前已引起人们很大的注意. 预计它将开辟永磁材料中的一个新的大领域.

\section{二、基本原理简述}

$\mathrm{Fe}-\mathrm{Cr}-\mathrm{Co}_{0}$ 系永磁合金的磁硬化机理, 是过饱和的体心立方固溶体 ( $\alpha$ ) 在某种条件下所 发生的脱溶过程, 即: $\alpha \rightarrow \alpha_{1}+\alpha_{2}$ 。

其中 $\alpha_{1}$ 是富铁、钴的微粒铁磁性析出相, $\alpha_{2}$ 是富铬.(贫铁、钴)的非磁性基体相 ( $\alpha_{1}$ 和 $\alpha_{2}$ 也 都是体心立方型的固溶体)。这种过饱和固溶体的脱溶过程，是以斯皮诺答尔分解方式进行 的 ${ }^{[6-10]}$.

斯皮诺答尔分解的特点是:

（1）析出相,不是由于形核长大过程来完成的,而是由于固溶体基体里溶质原子的浓度起 伏的连续变大来完成的. 所以,析出相不受位错和其他晶格缺陷的影响,而且这种微细的析出 相是呈均匀分布的.

（2）在固溶体分解的初期,析出相与基体之间没有明显的边界,而是完全的共格状态.

（3）分解时,不需要克服势垒的激活能,所以不需要象形核机理中那样的孕育期.

（4）析出相的粒度取决于浓度起伏的波长. 而浓度起伏的波长，是依赖于它的成分和温 度的,对固定成分而言,温度高则波长大. 在一定成分和一定温度下，浓度起伏的振幅随着时 间的增长而变大,但浓度起伏的波长却难以随保温时间的增长而增长. 这表明不会出现“过时 效”现象, 即保证了析出相的微细性.

（5）发生斯皮诺答尔分解时,其合金组织呈现调幅结构 (Modulated structure).

（6）斯皮诺答尔分解,是各向异性的. 例如,外加应力和磁场等就与这种分解进程有关.

只要找到 $\mathrm{Fe}-\mathrm{Cr}-\mathrm{Co}$ 系合金的斯皮诺答尔分解的发生条件，便会获得良好的永磁性能. 又因为 $\alpha$ 单相具有好的塑性,这就决定了合金在该状态下具有良好的加工性能. 


\section{$\equiv 、 \mathbf{F e}-\mathbf{C r}-\mathrm{Co}_{0}$ 合金}

$\mathrm{Fe}-\mathrm{Cr}-\mathrm{Co}$ 合金的状态图, 已有报道 ${ }^{[7,11]}$. 此处仅选取 $1200^{\circ} \mathrm{C}$ 时的 $\mathrm{Fe}-\mathrm{Cr}-\mathrm{Co}$ 三元系 状态图 ${ }^{[4]}$,及含有 $\mathrm{Fe} 60 \%$ 时纵断面的示意状态图 ${ }^{[4,7]}$, 作为示例.

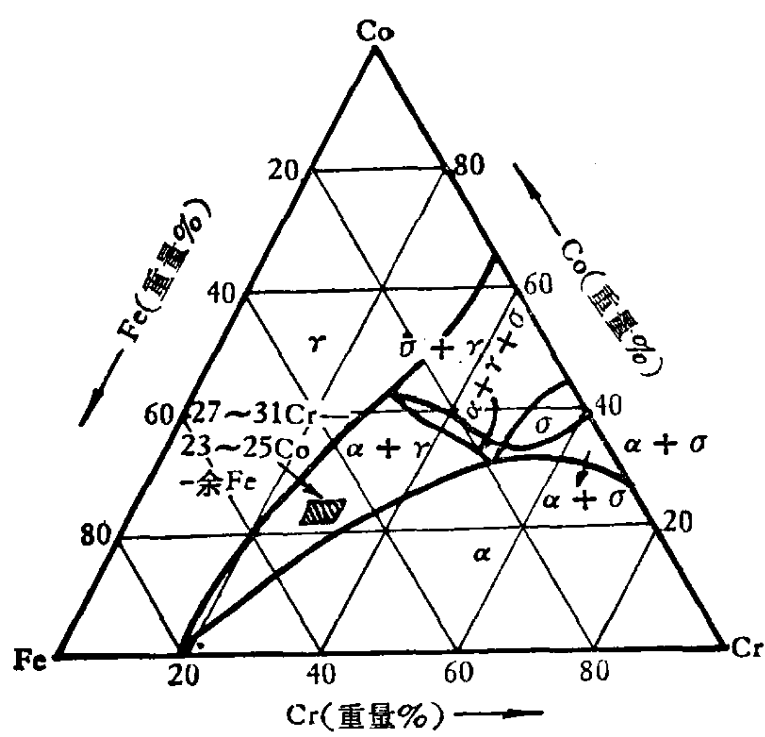

图 $21200^{\circ} \mathrm{C}$ 下的 $\mathrm{Fe}-\mathrm{Cr}-\mathrm{Co}$ 三元系状态图 ${ }^{[4]}$

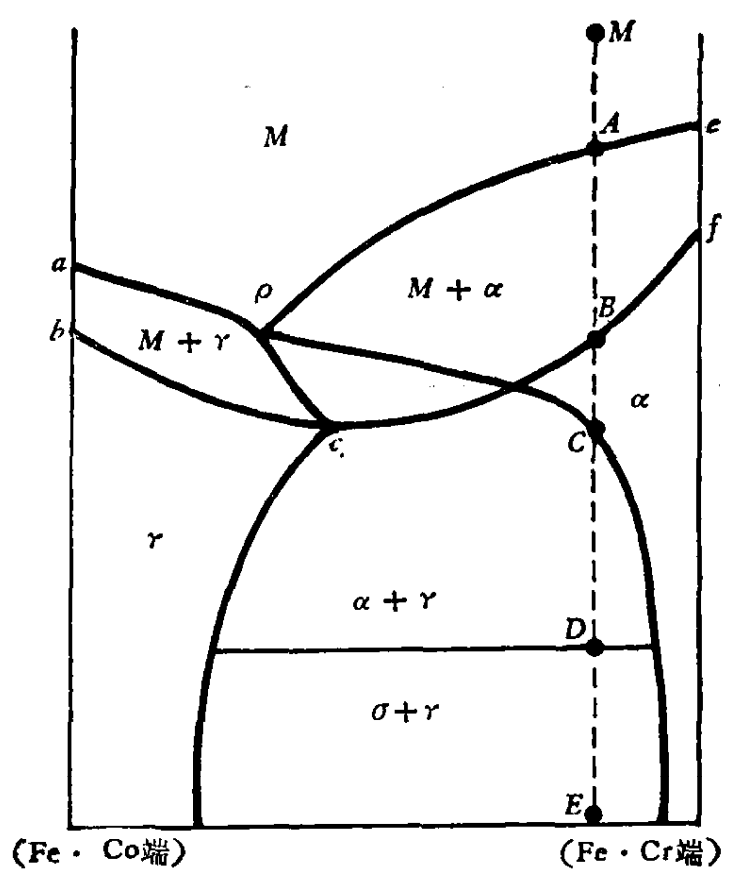

图 3 含有 $\mathrm{Fe} 60 \%$ 时纵断面示意状态图 ${ }^{[7]}$

由图 2 可知, 合金在 $1200^{\circ} \mathrm{C}$ 下大体上处于 $\alpha$ 相区, 低于此温度即析出有害的 $\gamma$ 相和 $\sigma$ 相. 锻造和热轧必须在 $\alpha$ 相或 $(\alpha+\gamma)$ 相温区内进行. 冷轧, 必须在由淬火所得到的 $\alpha$ 相或 $(\alpha+$

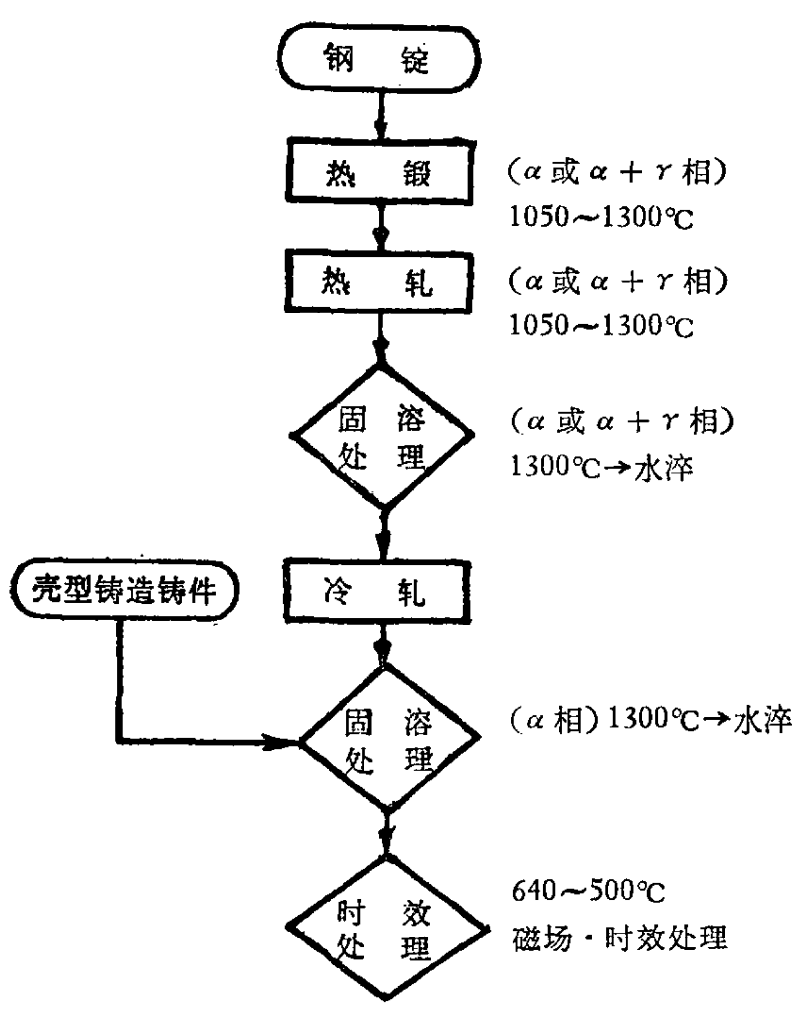

图 $4 \mathrm{Fe}-\mathrm{Cr}$ - $\mathrm{Co}$ 系合金的制造工艺 $\gamma$ ) 相状态下进行. 已知, 获得单一的 $\alpha$ 单 相，也是进行斯皮诺答尔分解 $\left(\alpha \rightarrow \alpha_{1}+\right.$ $\left.\alpha_{2}\right)$ 的必备条件. 例如图 3 中选定的 $M$ 点 合金，在 $B C$ 温区是 $\alpha$ 单相，若把该温度 下的状态水淬，即可在常温下把 $\alpha$ 相保持 下来.此时 $\alpha$ 相是不稳定的, 它本应转变为 $\sigma$ 相的. 若把 $\alpha$ 相状态的合金进行适当的 处理, 即可发生斯皮诺答尔分解. 在 $B C$ 温区的 $\alpha$ 相和 $C D$ 温区的 $(\alpha+\gamma)$ 相状态

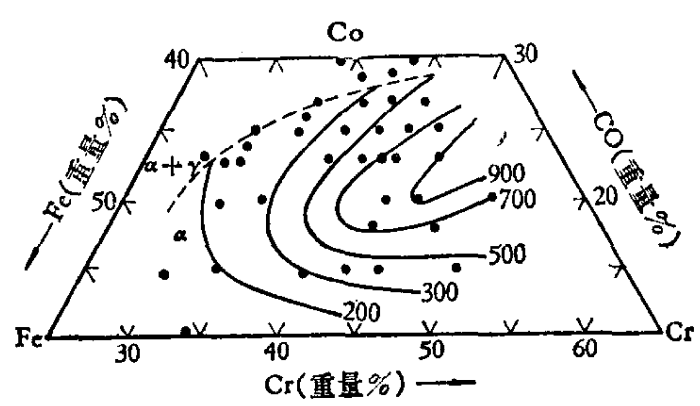

图 $5 \mathrm{Fe}-\mathrm{Cr}-\mathrm{Cu}$ 合金的矫顽力 $(\mathrm{iHc})^{[1, \ldots, 12]}$ 
下,便可进行塑性加工的. 图 4 示出该类合金的制造工艺. 图 5 给出了经 $1300{ }^{\circ} \mathrm{C}$ 水淬和 $610^{\circ} \mathrm{C}$ 8 小时以上回火后所得到的最高矫顾力的分布图. 由图可知, 矫顽力随 Co 含量增加而提高, 当 $\mathrm{Co}$ 为 $20 \%$ 时,则它为 900 奥斯特.

表 $5 \mathrm{Fe}-\mathrm{Cr}-\mathrm{Co}$ 合金有或无磁场时的处理结果比较

\begin{tabular}{|c|c|c|c|c|c|c|c|}
\hline \multirow{2}{*}{ 合金(重量\%) } & 末 & 处 & 艺 & 磁 & 性 & 能 & \multirow{2}{*}{ 资 料 } \\
\hline & 溶 & 热 & 火 & $\begin{array}{c}\mathrm{Br} \\
\text { (高斯) }\end{array}$ & $\underset{\text { （奥斯特） }}{\mathrm{Hc}}$ & 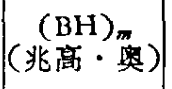 & \\
\hline $\begin{array}{l}\mathrm{Fe}-31 \mathrm{Cr}- \\
23 \mathrm{Co}\end{array}$ & $\underbrace{1300^{\circ} \mathrm{C} \times 30 \text { 分 }}_{\text {水 }}$ & $\begin{array}{l}640^{\circ} \mathrm{C} \times 30 \text { 分 } \\
(4000 \text { 奥磁场 })\end{array}$ & $\begin{array}{c}600^{\circ} \mathrm{C} \times 2 \text { 小时 }+580^{\circ} \mathrm{C} \\
\times 4 \text { 小时 }\end{array}$ & 11500 & 660 & 4.1 & $\begin{array}{l}{[1]} \\
{[13]}\end{array}$ \\
\hline 同 & 同 & $\begin{array}{l}640{ }^{\circ} \mathrm{C} \times 40 \text { 分 } \\
(4000 \text { 奥磁场 })\end{array}$ & $\begin{array}{l}600{ }^{\circ} \mathrm{C} \times 1 \text { 小时 }+580^{\circ} \mathrm{C} \\
\times 1 \text { 小时 }+560^{\circ} \mathrm{C} \times 6 \text { 小时 }\end{array}$ & 11800 & 680 & 4.5 & [ 2$]$ \\
\hline 同 & 同 & $\begin{array}{l}640^{\circ} \mathrm{C} \times 30 \text { 分 } \\
\text { (无磁场) }\end{array}$ & $\begin{array}{c}600^{\circ} \mathrm{C} \times 2 \text { 小时 }+580^{\circ} \mathrm{C} \\
\times 4 \text { 小时 }\end{array}$ & 8400 & 630 & 2.2 & $\begin{array}{l}{[1]} \\
{[13]}\end{array}$ \\
\hline
\end{tabular}

由表 5 结果可知, 在斯皮诺答尔分解过程中,施加外磁场时则有利于磁性能. 这是斯皮诺 答尔分解时具有各向异性的效果.

已知淬火处理的目的, 是使高温下的 $\alpha$ 相保存下来, 淬火时的临界冷却速度为 $60^{\circ} \mathrm{C} /$ 秒 $^{\{21}$. 回火时间与磁性能的关系见图 6 所示 $\left(1300^{\circ} \mathrm{C}\right.$ 水淬, $640^{\circ} \mathrm{C} \times 30$ 分热磁处理).

\section{四、 $\mathrm{Fe}-\mathrm{Cr}-\mathrm{Co}-\mathrm{Mo}$ 合金}

把 3\% (重量)钼加到 $\mathrm{Fe}-\mathrm{Cr}-\mathrm{Co}$ 三元系里, 可以改善合金的磁性能. 在钼为定值的情

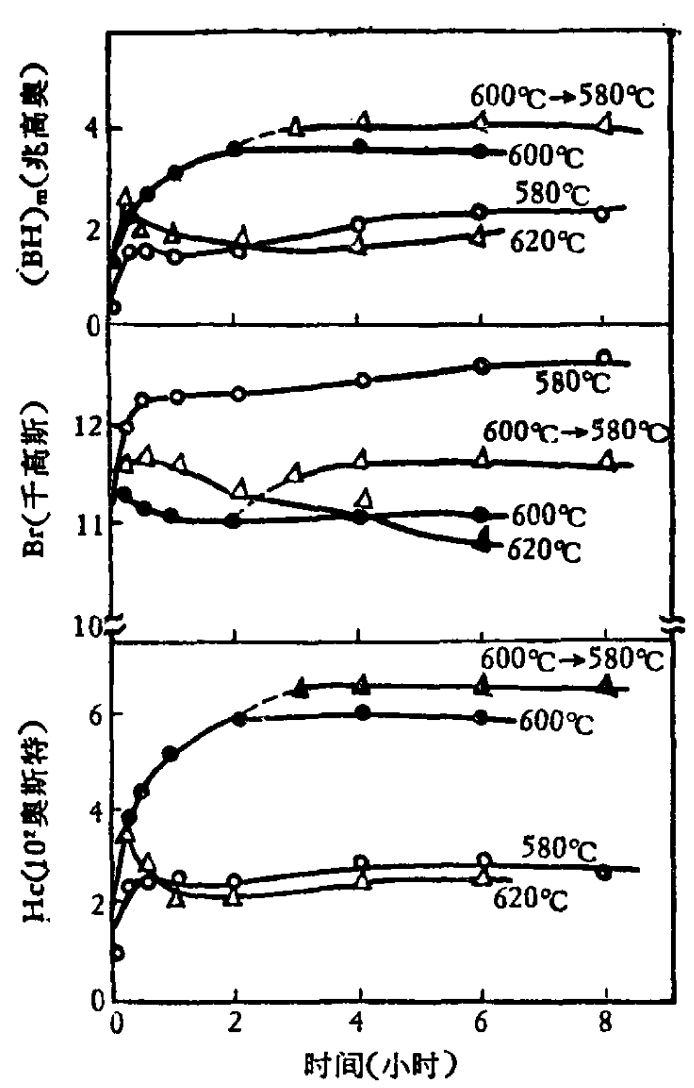

图 $6 \mathrm{Fe}-31 \% \mathrm{Cr}-23 \% \mathrm{Co}$ 合金的聯性 与回火时间的关系 ${ }^{[1]}$ 况下 ( $3 \% \mathrm{Mo})$ ，就整个合金范围测定了矫硕力和 剩 磁,其结果示于图 7 和图 8 中 ${ }^{[7]}$. 由图 7 可知,加锄 后的合金,其矫顽力最高可达 1100 奥斯特. 由图 8 可知,剩磁最大可达 12000 高斯.

对 $\mathrm{Fe}-30 \% \mathrm{Cr}-25 \% \mathrm{Co}-3 \% \mathrm{Mo}$ 合金的热处 理研究结果表明 ${ }^{[14]}$ :

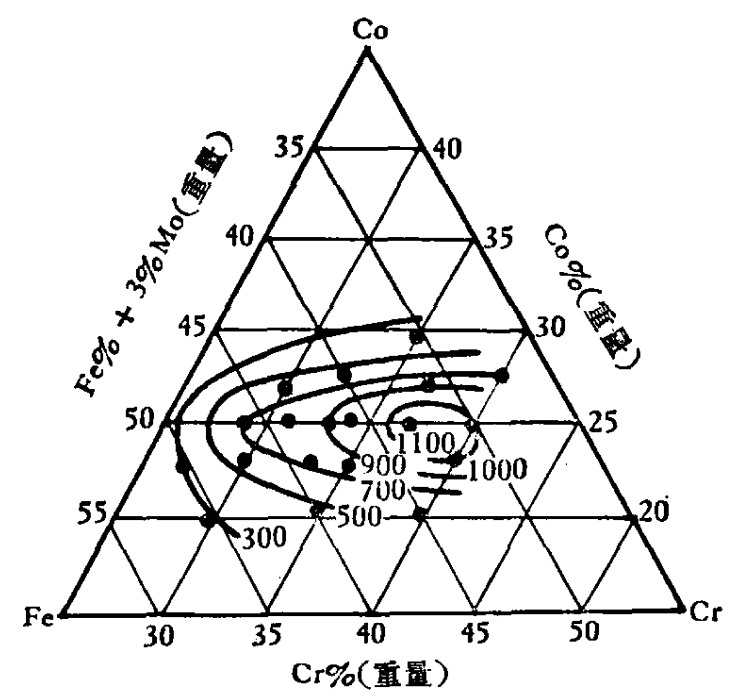

图 $7 \mathrm{Fe}-\mathrm{Cr}-\mathrm{Co}-\mathrm{Mo}$ 斯皮诺答尔型永磁合金的 $\mathrm{Hc}$ (奥) 
（1）热磁处理温度对磁性有显著的影响. 这个最佳温度范围是 $610 \sim 640^{\circ} \mathrm{C}$.

(2) 经 $600^{\circ} \mathrm{C}$ 初级回火后, 再进行 $550 \sim 580^{\circ} \mathrm{C}$ 次级回火处理, 磁能积上升.

（3）热磁处理时，磁性能随着磁场强度的增大而增高，当磁场强度达到 2000 奥斯特以上 时,则磁性能大体趋于恒定.

有关实验结果见表 6.

表 $6 \mathrm{Fe}-\mathrm{Cr}-\mathrm{Co}-\mathrm{Mo}$ 合金热处理工圭和磁性能

\begin{tabular}{|c|c|c|c|c|c|c|c|c|c|}
\hline \multirow{2}{*}{$\begin{array}{l}\text { 合 金 } \\
\text { （重量\%） }\end{array}$} & 热 & 夕 & 理 & 工 & 艺 & 磁 & 性 & 能 & \multirow[b]{2}{*}{ 资 料 } \\
\hline & 固 & 热 & 磁 & 回 & 火 & $\begin{array}{c}\mathrm{br} \\
\text { (高斯) }\end{array}$ & $\begin{array}{c}\mathrm{Hc} \\
\text { (舆斯特) }\end{array}$ & $\left|\begin{array}{r}(\mathrm{BH})_{m} \\
\text { (兆高・奥) }\end{array}\right|$ & \\
\hline $\begin{array}{l}\mathrm{Fe}-30 \mathrm{Cr}- \\
25 \mathrm{Co}-3 \mathrm{Mo}\end{array}$ & $\begin{array}{c}1330^{\circ} \mathrm{C} \times 30 \text { 分 } \\
\text { 水 淬 }\end{array}$ & $\begin{array}{l}630^{\circ} \\
(400\end{array}$ & 30 分 & $\begin{array}{c}600^{\circ} \mathrm{C} \\
10^{\prime}\end{array}$ & $\begin{array}{l}4 \text { 小时 }+580^{\circ} \mathrm{CX} \\
\text { 时 }\end{array}$ & 11200 & 730 & 5.0 & {$[14]$} \\
\hline 上 & $\begin{array}{c}1300^{\circ} \mathrm{C} \times 30 \text { 分 } \\
\text { 水 淬 }\end{array}$ & $\begin{array}{l}630^{\circ} \\
(400\end{array}$ & 30 分 & $\begin{array}{r}600^{\circ} \mathrm{C} \\
4 \text { 小 }\end{array}$ & 2 小时 $+580^{\circ} \mathrm{C} \times$ & 11500 & 780 & 5.0 & {$\left[\begin{array}{r}1 \\
{[13]}\end{array}\right]$} \\
\hline
\end{tabular}

\section{五、 $\mathrm{Fe}-\mathrm{Cr}-\mathrm{Co}-\mathrm{Si}$ 合金}

研究表明, 在 $\mathrm{Fe}-\mathrm{Cr}-\mathrm{Co}$ 三元系里, 添加适当量的硅, 可以改善合金的磁性和冷热塑性.

(1) 合金成分的研究

把钴含量固定为 $23 \%$, 并分别在无硅、 $1 \%$ 硅和 $2 \%$ 硅的三种情况下 来改变铬含量（24～ $36 \%)$, 其研究结果示于图 $9^{[2,3]}$.

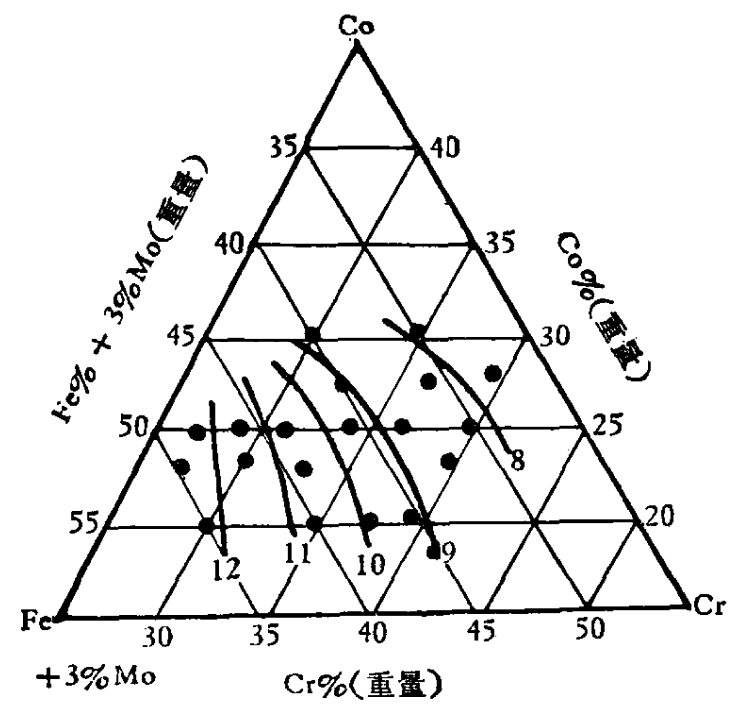

图 $8 \mathrm{Fe}-\mathrm{Cr}-\mathrm{Co}-\mathrm{M}$ o 斯皮诺答尔型永磁 合金的 $\mathrm{Br}$ (千高)

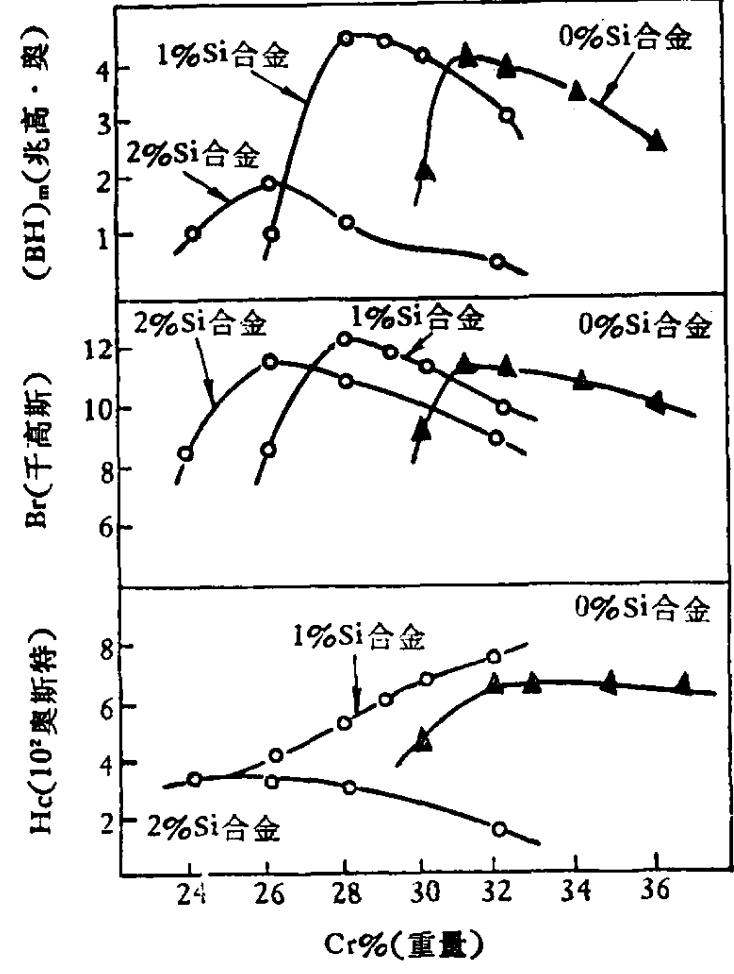

图 $9 \mathrm{Fe}-\mathrm{Cr}-\mathrm{Co}$ 和 $\mathrm{Fe}-\mathrm{Cr}-\mathrm{Co}-\mathrm{Si}$ 合金的磁性

热处理条件: $1.1300^{\circ} \mathrm{C} \times 30$ 分, 水淬; $2.640^{\circ} \mathrm{C} \times 40$ 分 ( 4000 奥下)； $3.600^{\circ} \mathrm{C} \times 2$ 小时 $+580^{\circ} \mathrm{C} \times 4$ 小时.

结果: 含 $1 \%$ 硅的为好，其相应的最佳成分为： $\mathrm{Fe}-28 \% \mathrm{Cr}-23 \% \mathrm{Co}-1 \% \mathrm{Si}$ 。该合金的 最佳磁性能为: $\mathrm{Br}=13000$ 高斯, $\mathrm{Hc}=580$ 奥斯特, $(\mathrm{BH})_{m}=5.3$ 兆高 - 奥.

在 $24 \sim 31 \% \mathrm{Cr}, 23 \sim 24 \% \mathrm{Co}, 0.5 \sim 1.5 \% \mathrm{Si}$, 余为 $\mathrm{Fe}$ 的范围内进行研究的结果表明 ${ }^{[4]}$, 硅 
若超过 $1 \%$ 则磁性便下降. 所得到的合适成分为: $\mathrm{Fe}-27 \sim 28 \% \mathrm{Cr}-23 \% \mathrm{Co}-0.7 \sim$ $1.0 \% \mathrm{Si}$ 和 $\mathrm{Fe}-31 \% \mathrm{Cr}-24 \% \mathrm{Co}-0.6 \sim 0.9 \% \mathrm{Si}$. 其所获得的磁性能: $\mathrm{Br}=11000 \sim$ 11900 高斯, $\mathrm{Hc}=725 \sim 763$ 奥斯特, $(\mathrm{BH})_{m}=4.3 \sim 5.0$ 兆高. 奥. 现把其中有代表性的 合金的磁性列于表 7 .

表 7 合金 $\mathrm{Fe}-27.71 \% \mathrm{Cr}-23.06 \% \mathrm{Co}-0.82 \% \mathrm{Si}$ 的最佳磁性

\begin{tabular}{|c|c|c|c|c|c|c|c|c|}
\hline (高 ${ }^{\mathrm{Br}}$ 斯) & （奥 & $\begin{array}{l}\text { Hc } \\
\text { 斯 特) }\end{array}$ & $\left(\begin{array}{c}(\mathrm{BH})_{m} \\
(\text { 兆高 - 奥) }\end{array}\right.$ & 热 & 处 & 理 & 条 & 件 \\
\hline 11900 & & 725 & 5.0 & \multicolumn{5}{|c|}{$\begin{array}{l}1330^{\circ} \mathrm{C} \times 30 \text { 分, 水淬 } \\
640^{\circ} \mathrm{C} \times 30 \text { 分 }(4000 \text { 舆下 }) \\
600^{\circ} \mathrm{C} \times 1 \text { 小时 }+580^{\circ} \mathrm{C} \times 4 \text { 小时 }+560^{\circ} \mathrm{C} \times 8 \text { 小 }\end{array}$} \\
\hline
\end{tabular}

(2) 热处理的研究

固溶处理的目的,是使合金形成单一的 $\alpha$ 相,是进行下一步热磁处理和回火处理的必备条 件. 因此,固溶处理的好或坏,会明显地影响到最后的性能好或坏. 本合金的固溶处理工艺为 $1300^{\circ} \mathrm{C} \times 30$ 分水淬 ${ }^{[2,3]}$, 或 $1330^{\circ} \mathrm{C} \times 30$ 分水淬 ${ }^{[4]}$. 根据固溶处理后试样的饱和磁化强度 $(4 \pi \mathrm{Is})$ 的大小, 可以判断 $\alpha$ 单相的形成状况. 加人硅, 可以降低淬火时的临界冷却速度, 例如, $\mathrm{Fe}-$ $28 \% \mathrm{Cr}-23 \% \mathrm{Co}-1 \% \mathrm{Si}$ 的合金，其淬火时的临界冷却速度为 $10^{\circ} \mathrm{C} /$ 秒 $^{[2]}$. 因为淬火效果与材 料尺寸有关, 所以降低淬火时的临界冷却速度是有利于工业生产的. 研究表明, 本系合金淬火 时材料的最大尺寸：直径或厚度约为 20 毫米左右 ${ }^{[4]}$.

图 10 给出了 $\mathrm{Fe}-27 \% \mathrm{Cr}-23 \% \mathrm{Co}-1 \% \mathrm{Si}$ 合金的冷速与相变的关系.

由图 11 可知, 在 $620^{\circ} \mathrm{C} 8$ 小时的时候, $\mathrm{Br}$ 和 $\mathrm{Hc}$ 进一步增大. 由图 12 看到, 在外加磁场 下的处理是卓有成效的. 当磁场强度超过 2000 奥斯特时, 磁性急剧地增高,在 3000 奥斯特下 大致达到饱和. 磁场大于 3000 奥斯特时,其 $\mathrm{Br}$ 和 $(\mathrm{BH})_{m}$ 还有微量增加.

以表 7 中所示成分的合金进行了回火工艺的研究(图 13)，表明多级回火为好. 其所得到 的最高磁性能为: $\mathrm{Br}=11900$ 高斯, $\mathrm{Hc}=725$ 奥斯特, $(\mathrm{BH})_{m}=5.0$ 兆高. 奥.

还有,如表 8 所列的实验结果,也表明三级回火为好.

(3) 加工性能研究 ${ }^{[4]}$

本系合金的特点, 是可以进行机械加工的. 机械加工要在 $\alpha$ 相或 $(\alpha+\gamma)$ 相的状态下进 行. 锻造和热轧的开始温度为 $1250 \sim 1300^{\circ} \mathrm{C}$, 终了温度以 $1050^{\circ} \mathrm{C}$ 以上为宜. 为了防止锻造

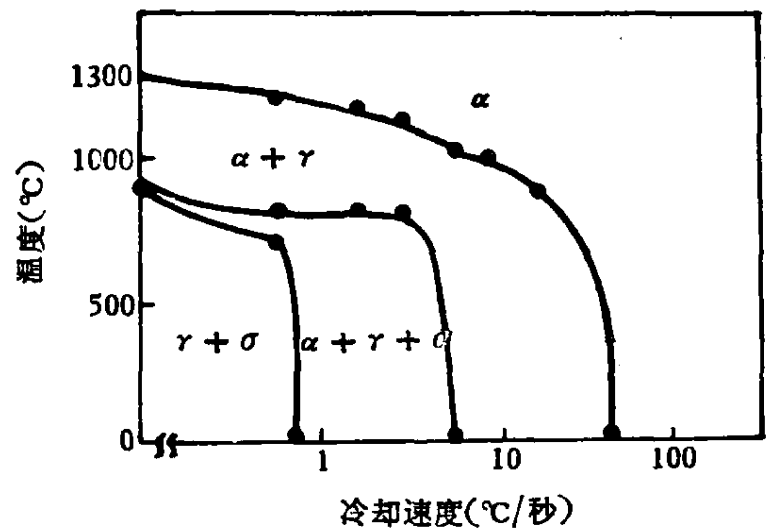

图 $10 \mathrm{Fe}-27 \% \mathrm{Cr}-23 \% \mathrm{Co}-1 \% \mathrm{Si}$ 合金的 冷速与相变的关系 ${ }^{[4]}$

$1330^{\circ} \mathrm{C} \times 30$ 分, 水淬

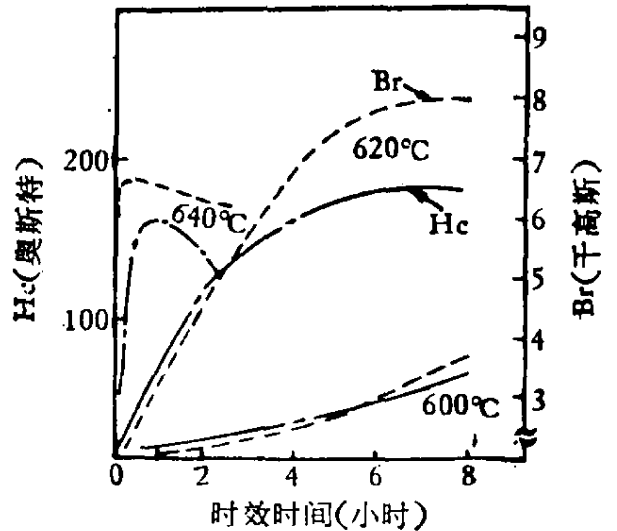

图 11 各种时效处理下的 $\mathrm{Hc}$ 和 $\mathrm{Br}$ 的变化 合金为表 7 所示的成分 (试样尺寸 $\phi 13 \times 12$ ). 固溶处理: $1330^{\circ} \mathrm{C} \times 30$ 分, 水淬 


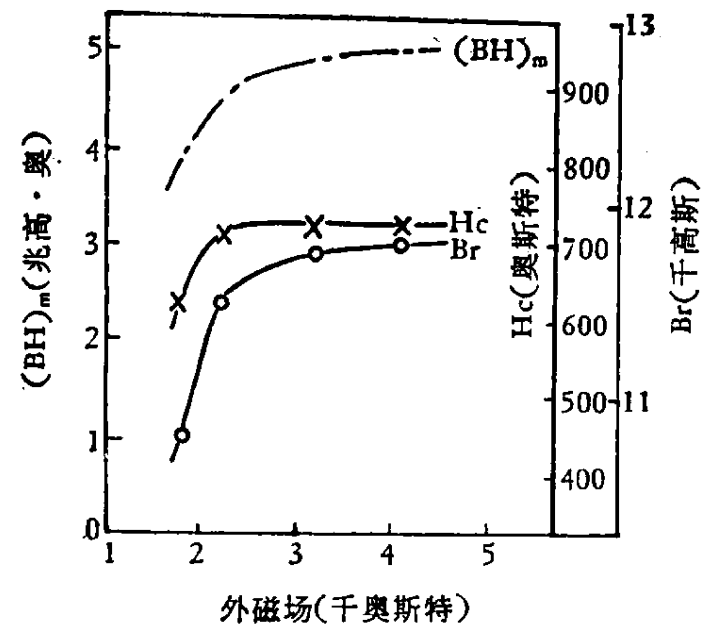

图 12 磁场处理时外磁场强度和磁性的关系 ${ }^{[4]}$

合金为表 7 所示的成分(试样尺寸 $\phi 13 \times 12$ ). 固溶处理： $1330^{\circ} \mathrm{C} \times 30$ 分,水淬; 磁场处理： $640^{\circ} \mathrm{C} \times 30$ 分; 回火处理: $600^{\circ} \mathrm{C} \times 1$ 小时 + $580^{\circ} \mathrm{C} \times 4$ 小时 $+560^{\circ} \mathrm{C} \times 8$ 小时
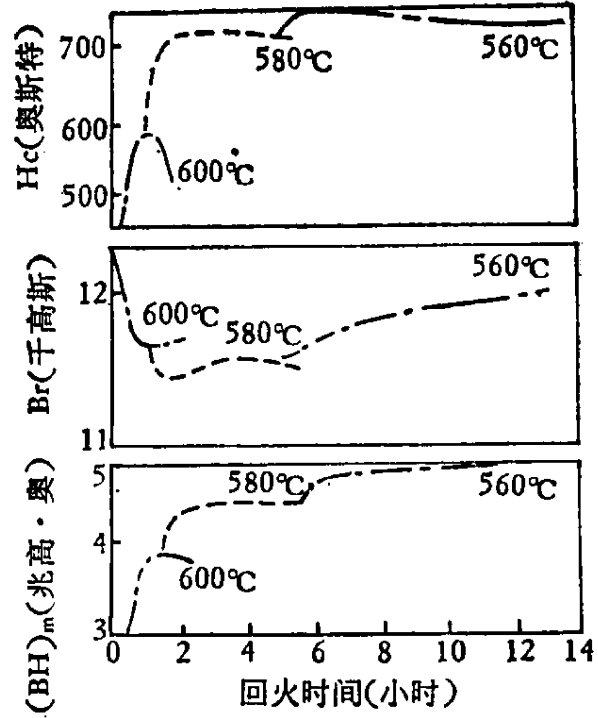

图 13 回火处理与磁性的关系 ${ }^{[4]}$

合金为表 7 所示成分 (试样尺寸 $\phi 13 \times 12$ ). 固溶处理: $1330^{\circ} \mathrm{C} \times 30$ 分,水淬; 热磁处理: $640^{\circ} \mathrm{C} \times 30$ 分 $(4000$ 奧磁场 下)

表 8 二级回火和三级回火的比较 ${ }^{[2]}$

\begin{tabular}{|c|c|c|c|c|c|c|}
\hline \multirow{2}{*}{$\begin{array}{l}\text { 合 金 } \\
\text { (重量\%) }\end{array}$} & 热 & 理 & 工 & 磁 & 性 & 能 \\
\hline & 固 & 热 & 回 & (高 ${ }^{\mathrm{Br}}$ 斯) & $\begin{array}{c}\mathrm{Hc} \\
\text { (奥斯特) }\end{array}$ & $\begin{array}{c}(\mathrm{BH})_{m} \\
(\text { 兆高・奥 })\end{array}$ \\
\hline \multirow{2}{*}{$\begin{array}{c}\mathrm{Fe}-31 \% \mathrm{Cr}- \\
23 \% \mathrm{Co}\end{array}$} & \multirow[t]{2}{*}{$1300^{\circ} \mathrm{C} 30$ 分, 水淬 } & \multirow{2}{*}{$\begin{array}{c}6400^{\circ} \mathrm{C} \times 40 \text { 分 } \\
(4000 \text { 奥磁场下) }\end{array}$} & $600^{\circ} \mathrm{C} \times 2$ 小时 $+580^{\circ} \mathrm{C} \times 4$ 小时 & 11500 & 660 & 4.1 \\
\hline & & & $\begin{array}{l}600^{\circ} \mathrm{C} \times 1 \text { 小时 }+580^{\circ} \mathrm{C} \times 1 \text { 小时 } \\
+560^{\circ} \mathrm{C} \times 6 \text { 小时 }\end{array}$ & 11800 & 680 & 4.5 \\
\hline \multirow{2}{*}{$\begin{array}{c}\mathrm{Fe}-28 \% \mathrm{Cr}- \\
23 \% \mathrm{Co}- \\
1 \% \mathrm{Si}\end{array}$} & \multirow[t]{2}{*}{$1300^{\circ} \mathrm{C} 30$ 分, 水淬 } & \multirow{2}{*}{$\begin{array}{c}640^{\circ} \mathrm{C} \times 40 \text { 分 } \\
(4000 \text { 奥磁场下) }\end{array}$} & $600^{\circ} \mathrm{C} \times 2$ 小时 $+580^{\circ} \mathrm{C} \times 4$ 小时 & 12500 & 510 & 4.4 \\
\hline & & & $\begin{array}{l}600^{\circ} \mathrm{C} \times 1 \text { 小时 }+580^{\circ} \mathrm{C} \times 1 \text { 小时 } \\
+560^{\circ} \mathrm{C} \times 6 \text { 小时 }\end{array}$ & 13000 & 580 & 5.3 \\
\hline
\end{tabular}

和热轧后可能析出 $\sigma$ 相而造成裂痕, 所以在冷轧前需要再进行适当的固溶处理. 真空中冶炼 的材料比起空气中冶炼的材料来,其高温加工性能要好得多.

\section{参考 资料}

[1] Kaneko, H., Homma, M., Magnetism and Magnetic Materials, 1971, 1088.

[2] Kaneko, H., et al., I. E. E. E. Trans. Magnetics, MAG-8 (1972), 347.

[3] Kaneko, H., et al., Cobalt, 1973, 2, 25.

[4] 㨉井正美、铃木貝蝴,三菱製鋼技報，6 (1972)，2，91。

[5] 金子秀夫,日本金属学会シンボジウム講演预稿,昭和 47 年, 275.

[6] Cahu, J. W., Acta. Met., 9 (1961), 795; Cahu, J. W., J. Chem. phys., 42 (1965), 93.

[ 7] 金子秀夫,金属, 42 (1972), 1, 106.

[8]矢島说次郎,宫崎亭,热处理 12 (1972), 2, 139.

[9] 矢島说次郎,宫崎亭,热处理, 12 (1973), 3, 203.

[10] 岩間義郎,日本金属学会会報, 12 (1973), 5, 289 .

[11] West, D. R. F., Cobalt, 51 (1971), 77.

[12] 神谷、铃木, 日本電子材料技術協会講演概要，1971，22。

[13] Kaneko, et al., Cobalt, 1972, 54, 47.

[14] 金子秀夫, 日本金属学会講演概要, 1971, 4, 169 . 